\title{
The effect of Zumba exercises on body composition, dynamic balance and functional fitness parameters in 15-17 years old women with high body mass index
}

\author{
Eroğlu Kolayiş I. ${ }^{1 \mathrm{ABCDE}}$, Arol P. ${ }^{2 \mathrm{ABDE}}$ \\ ${ }^{1}$ Department of Recreation Faculty of Sport Sciences, Sakarya University of Applied Sciences, Turkey \\ ${ }^{2}$ Adapazarl Vocational and Technical Anatolian High School, Turkey
}

Authors' contributions: A - Study design; B - Data collection; C - Statistical analysis; D - Manuscript Preparation; E - Funds Collection.

\begin{abstract}
Purpose:

The aim of this study was to investigate the changes in body composition-dynamic balance and functional movement capacity of 60 female high school students with body mass index (BMI) over 24.9 before and after the eight-week zumba exercise program.

Material: $\quad$ The study included 60 volunteer healthy young women whose body mass index was higher than 24.9 (mean age: $16.75 \pm 0.43$ years, mean weight: $75.99 \pm 10.91 \mathrm{~kg}$, mean body fat: $36.83 \pm 6.1 \%$, BMl: 29.56 \pm 4.12). The portable stadiometer Seca-213 was used to determine the lengths of the study group. TANITA-Bc $545 \mathrm{~N}$ Innerscan Segmental Body Composition Analyzer, "Y-Balance Test was implemented to determine the dynamic balance values for the lower and upper extremities, Functional Movement Screen (FMS) test, was used to determine functional movement capacity. To determine the number of heart beats during zumba exercises, Polar M430 Heart Rate Monitor was used and a total of 24 zumba exercise sessions were conducted from three days a week for eight weeks.

Results: $\quad$ According to the findings of the study, during the 8-week zumba training program, it is seen that it provided statistically significant improvement in total body weight loss $(p=.000)$, BMI parameter $(p=.000)$, body fat $\%(p=.002)$, FMS values $(p=.000)$ and lower an upper extremity dynamic balance parameters $(p=.000)$.

Conclusions: It was found that the eight-week zumba training program had positive effects body composition values, functional mobility assessment results and dynamic balance parameters of high school students with a high body mass index of 15-17 years of age.

Keywords: zumba, dynamic balance, FMS, body fat, high BMI.
\end{abstract}

\section{Introduction}

In recent years, overweight and obesity in childhood and adolescence have become an important health problem all over the world, especially in developed countires due to the decrease in physical activity [1]. The World Health Organization (WHO) stated that approximately $40 \%$ of individuals over the age of 18 were overweight [2], and studies have shown that the rate of overweight and obesity is more common in women than in men [3]. In Turkey, as in similar studies carried out worldwide prevalence, rate of overweight and obesity was higher in women compared to men [4]. Concerns about the appearance of women's bodies are effective not only during adolescence but at every stage of their lives [5]. Therefore, positive changes in physical perception affect daily life positively. In order to achieve this effect, it is very important that regular physical activity takes place in daily life. Studies have shown that sedentary lifestyle is one of the leading factors that increase overweight and obesity $[6,7]$. Many countires around the world are looking for ways to struggle against overweight, obesity and lack of physical activity. Regular physical activities such as walking, plates, zumba appear to be one of the most effective and popular methods for preventing obesity, weight loss and body tightening among women with nutrition [5, 8]. Long-term monotonous training contents of exercise programs are one of the reasons why phsyical activities cannot be sustained regularly [9]. Although they exercise with music and movements, they do not feel like working out while performing zumba exercises. Therefore these are effective ways to prevent sedentary lifestyle. It also provides a disguised fitness activity atmosphere with its pleasant way of exercising to prevent overweight and obesity. Zumba exercises that can be practiced easily by all individuals starting from the age of 4 with competent trainers, which attracted 14 million participants in 150 countries, and are among the top 10 sports trends: it is a very popular Latin-dance sports program $[10,11]$. One of the reasons for its popularity today is that there is no right or wrong method in zumba exercise practices. Zumba activities, whose motto is "put aside the training and join the party" causes individuals to engage in physical activity by making them want to repeat the exercises with fun content [9]. Zumba exercises; improves strength, balance, coordination and fitness as well as improving the rate of fat reduction in women is a dynamic study to change the body composition in a positive way [12-14].

The concept of balance, which is capable of keeping the center of gravity within acceptable limits of the support surface in daily physical activities [15], is learned and developable skill and has an important role in performing functional movements in daily life [16]. Studies have shown that adipose tissue deposition and low 
physical activity levels decrease body balance and create a positive correlation between high BMI and postural instability. In this case, it is observed that the individual will need more effort to maintain the postural balance [17]. Weak balance is known to be a risk factor for the occurrence of injuries during daily physical activity and athletic performance, especially in women [18]. Therefore, the balance-enhancing effect of regular zumba exercises appears to be an effective method in reducing these factors [13]. Functional movement is the ability to produce and maintain basic movements for activities that provide a balance between mobility and stability along the kinetic chain [19]. Many people do not have sufficient knowledge of how to do basic physical activities in their daily lives and this may cause problems in achieving the intended physical fitness criteria in the long term [20]. Functional Movement Screen (FMS) testing, which aims to simulate the needs and constraints of physical activity in daily life, as a screening tool to assess functional mobility and postural stability [21], should be considered for proper physical activity applications. It is a practical and important measurement method, and it is guiding in the estimation of dynamic balance scores in women and men $[22,23]$.

In spite of its popularity, there have been no studies dealing with all body composition parameters, functional movement capacity scores and dynamic balance values of lower and upper extremities of young zumba participants. In this respect, the general purpose of the study was to determine the changes in Body Composition-Dynamic Balance and Functional Movement Capacity of female high school students with body mass index (BMI) over 24.9 before and after the eight-week zumba exercise program.

\section{Hypothesis.}

Regular participation in 8-week zumba exercise can improve the body composition (body weight, body fat percentage, BMI parameters) of young female high school students with high BMI values.

8 -week zumba exercise applications can improve the dynamic balance control of the lower and upper extremities of the working group with functional movement capacity values, which are important parameters for disability prevention and healthy living.

Purpose. The aim of this study was to investigate the changes in Body Composition-Dynamic Balance and Functional Movement Capacity of 60 female high school students with body mass index (BMI) over 24.9 before and after the eight-week zumba exercise program within one group pre test-post test experimental design.

\section{Materials and Methods}

Participants. For the purpose of the study; 60 female (Xage; $16,75 \pm 0,43$ ) students participated in the study, who have higher than 24.9 BMI values (BMI; 29.56 \pm 4.12 ; body fat $\% ; 36.83 \pm 6.1$ ) and no physical and neurological diseases, no serious limb discomfort and no sports activity.
The portable stadiometer Seca-213 was used to determine the lengths of the study group. TANITABc $545 \mathrm{~N}$ Innerscan Segmental Body Composition Analyzer, "Y-Balance Test was implemented to determine the dynamic balance values for the lower and upper extremities, Functional Movement Screen (FMS) test, one of the determinants of functional mobility capacity, was performed to determine the values of physical fitness and injury risk. To determine the number of heart beats during zumba exercises, Polar M430 Heart Rate Monitor was used.

\section{Data Collection}

\section{Body Composition Measurements}

In order to determine body composition parameters of the study group, TANITA-Bc $545 \mathrm{~N}$ device was used in sports clothes and bare feet.

\section{Dynamic Balance Measurements}

Dynamic balance measurements were evaluated with the Y-Balance Test, a functional test that required strength, flexibility, neuromuscular control, stability, range of motion, balance and proprioception, taking into account corrected arm and leg length [24]. The test was applied in two parts in order to determine the dynamic balance values of the lower and upper extremities. In the first section, the lower extremity mesaurements were performed in the anterior/posterio-lateral and posterio-medial plane, and in the second section the upper extremity measurements were performed in the superior/inferior and medial plane. Lower limb lengths of the study group were performed before the test, from the lower edge of the anterior superior iliac spine of the right leg to the distal edge of the medial malleolus while the subject was in a supine position on a table; the length of the upper limb, C7 vertebral spine after defining the spine from the tip of the right middle finger to the end point measured in centimeters with a tape measure [25]. Sufficient warm-up time was given to all participants before the test, and after 5 minutes of rest, trial measurements were made. Pariticipants were asked to perform and complete the test by stretching the foot in the air as far as possible in the planes indicated on one leg without hands and waist in sports clothes. The highest value was recorded after three replicates [23, 25]. It was defined "combined balance test score":

\section{Relative (normalized) reach distance $(\%)=$ maximum reach distance/limb length $* 100$.}

Data were calculated separately for both arms and legs. Upper extremity applications were determined by the formula [26]:

\section{Relative (normalized) reach $(\%)=$ maximum reach distance/limb length * 100}

After body composition measurements and dynamic balance tests, FMS measurements were performed, scored and the results were analyzed.

Functional Movement Screen (FMS) Test

The FMS test protocol developed by Cook was used 
to evaluate functional movement [27]. A test consisting of 7 subtest (deep squat, hurdle step, in-line lunge, shoulder mobility, active straight leg raise, trunk stability pushup, and rotary stability) was shown to the research group to explain and demonstrate FMS movements to ensure consistency before testing. After two trials, the study group was tested and then 3 trial rights, approximately 5 seconds between each trial and 1 minute rest between each test. The results were evaluated according to Cook's instructions in the range of 0 to 3 points, depending on the quality of body movements and how it was performed.

\section{Zumba Fitness Program}

A total of 24 zumba exercise sessions were conducted from three days a week for eight weeks, and the studies were conducted by a certified zumba instructor as a 60-minute session between 16.00-17.00 hrs. Zumba choreographies were generated from movements with less strain on the skeletal muscle system, avoiding highintensity jumping movements suitable for the overweight study group. The warm-up part of zumba program is $8-10$ minutes and consists of basic dance steps without jumping and bouncing movements accompanied by gradually accelerating music tempo (tempo 120-140 bpm) and aims to increase body temperature, muscle blood flow, joint mobilization and psychological preparation. The mean phase of the zumba exercise, where the intensity was determined by changing music tempo in the study sections, was performed with approximately 10 zumba

Table 1. The training program for the study group songs in the tempo range of $140-160 \mathrm{bpm}$ and a resting time of 20-30 seconds was given between the songs [9]. During the study, Polar M430 Heart Rate Monitor was implanted to the person with the highest BMI value considering the possible risks in practice and the maximal heart rate was tracked according to the formula (208(0.7xAge)). In the last stage of the exercise, the cooling phase, the music gradually slowed down and the exercise was completed with a $120 \mathrm{bpm}$ paced song.

\section{Statistical Analysis}

It was used SPSS 22 software. Body Weight, BMI, Body Fat $\%$, FMS (functional mobility capacity), Lower Extremity Y-Balance Test values show normal distribution. Pre-test and post-test analyzes are not suitable for normal distribution. The significance level was determined as 0.05 . The body weight, BMI, Fat $\%$, dynamic balance, and functional mobility capacity of the study group which were changed during zumba exercises were calculated by the following formula:

\section{$\% \Delta=($ post-test-pre-test $) /$ pre-test $* 100$}

\section{Results}

According to the purpose of the research, the findings were as follows: the results of the body composition of the study group, the functional movement capacity (FMS) measurement results and results of the lower and upper extremity dynamic balance measurements are given in Table 2 and Table 3.

\begin{tabular}{|c|c|c|c|c|}
\hline Workout Plan & \multicolumn{3}{|l|}{ Content } & Duration \\
\hline $\begin{array}{l}\text { Starting-Warm- } \\
\text { up Part (8-10 } \\
\text { minutes) }\end{array}$ & \multicolumn{3}{|c|}{$\begin{array}{l}\text { Zumba dance movements consisting of basic dance steps without jumping } \\
\text { and bouncing movements at } 120-140 \text { bpm music pace, which lasts } \\
\text { approximately } 8-10 \text { minutes, gradually accelerating/resting time between } \\
\text { songs } 20-30 \text { seconds }\end{array}$} & \multirow{3}{*}{$\begin{array}{l}\text { Eight weeks } \\
\text { ( } 24 \text { sessions of } \\
\text { zumba sessions } \\
\text { each of which } \\
\text { consists of } 60 \\
\text { minutes) }\end{array}$} \\
\hline \multirow[t]{2}{*}{$\begin{array}{l}\text { Mean Phase ( } 40- \\
45 \text { minutes) }\end{array}$} & \multicolumn{3}{|c|}{$\begin{array}{l}\text { Zumba dance moves with } 10 \text { zumba songs in the tempo range of } 140-160 \\
\text { bpm lasting approximately } 40-45 \text { minutes *Average Song time } 4.30 \mathrm{~min} / \\
\text { Rest time between songs } 20-30 \text { seconds }\end{array}$} & \\
\hline & \multicolumn{3}{|c|}{ Approximate } & \\
\hline $\begin{array}{l}\text { Cooldown } \\
\text { (approximately } 5 \\
\text { minutes) }\end{array}$ & \multicolumn{4}{|c|}{$\begin{array}{l}\text { Cooling and stretching movements at } 120 \mathrm{bpm} \text { tempo, which lasts } \\
\text { approximately } 5 \text { minutes and gradually slows down }\end{array}$} \\
\hline Indicators & Test & Mean & Development \% & Sig. (2-tailed) \\
\hline \multirow{2}{*}{ Weight (kg) } & Test & $75.99 \pm 10.91$ & \multirow{2}{*}{-4.16} & \multirow{2}{*}{$0.000^{*}$} \\
\hline & Re-test & $72.83 \pm 10.63$ & & \\
\hline \multirow{2}{*}{ BMI } & Test & $29.56 \pm 4.12$ & \multirow{2}{*}{-4.22} & \multirow{2}{*}{$0.000^{*}$} \\
\hline & Re-test & $28.319 \pm 3.98$ & & \\
\hline \multirow{2}{*}{ Body Fat \% } & Test & $36.83 \pm 6.1$ & \multirow{2}{*}{-3.75} & \multirow{2}{*}{$0.002^{*}$} \\
\hline & Re-test & $35.44 \pm 5.78$ & & \\
\hline \multirow{2}{*}{ FMS (score) } & Test & $13.7 \pm 2.53$ & \multirow{2}{*}{15.45} & \multirow{2}{*}{$0.000 *$} \\
\hline & Re-test & $15.82 \pm 1.98$ & & \\
\hline
\end{tabular}


Table 3. Study Group Upper and Lower Extremity Y Balance mean ( \pm SD) Test-retest

\begin{tabular}{|c|c|c|c|c|c|c|}
\hline Balance & Indicators & Test & $\begin{array}{l}\text { Left / } \\
\text { Right }\end{array}$ & $X \pm S$ & $\begin{array}{l}\text { Development } \\
\%\end{array}$ & Sig. (2-tailed) \\
\hline \multirow{16}{*}{ 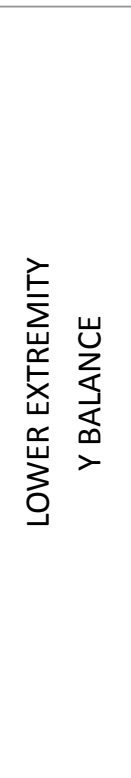 } & \multirow{4}{*}{ ANTERIOR (A) } & Test & \multirow{2}{*}{ Left } & $65.27 \pm 7.24$ & \multirow{2}{*}{5.22} & \multirow{2}{*}{$0.000^{*}$} \\
\hline & & Re-test & & $68.68 \pm 7.54$ & & \\
\hline & & Test & \multirow{2}{*}{ Right } & $66.52 \pm 6.92$ & \multirow{2}{*}{7.54} & \multirow{2}{*}{$0.000^{*}$} \\
\hline & & Re-test & & $71.54 \pm 7.08$ & & \\
\hline & & Test & \multirow{2}{*}{ Left } & $94.19 \pm 11.00$ & \multirow{2}{*}{2.01} & \multirow{2}{*}{$0.002 *$} \\
\hline & POSTFRO MFDIAI (PM) & Re-test & & $96.08 \pm 12.27$ & & \\
\hline & PUSIEKU IVIEUIAL (PIVI) & Test & \multirow{2}{*}{ Right } & $95.88 \pm 11.76$ & \multirow{2}{*}{3.41} & \multirow{2}{*}{$0.000 *$} \\
\hline & & Re-test & & $99.15 \pm 11.93$ & & \\
\hline & & Test & \multirow{2}{*}{ Left } & $95.13 \pm 10.46$ & \multirow{2}{*}{4.08} & \multirow{2}{*}{$0.000^{*}$} \\
\hline & POSTERO I ATFRAI (PI) & Re-test & & $98.99 \pm 11.13$ & & \\
\hline & PUSIERU LAIERAL (PL) & Test & \multirow{2}{*}{ Right } & $95.88 \pm 11.07$ & \multirow{2}{*}{4.41} & \multirow{2}{*}{$0.000^{*}$} \\
\hline & & Re-test & & $100.11 \pm 11.15$ & & \\
\hline & \multirow{4}{*}{$\begin{array}{l}\text { COMPOSITE reach distance } \\
(\%)\end{array}$} & Test & \multirow{2}{*}{ Left } & $84.87 \pm 8.28$ & \multirow{2}{*}{3.6} & \multirow{2}{*}{$0.000^{*}$} \\
\hline & & Re-test & & $87.92 \pm 8.59$ & & \\
\hline & & Test & \multirow{2}{*}{ Right } & $86.10 \pm 8.74$ & \multirow{2}{*}{4.85} & \multirow{2}{*}{$0.000^{*}$} \\
\hline & & Re-test & & $90.27 \pm 8.83$ & & \\
\hline \multirow{16}{*}{ 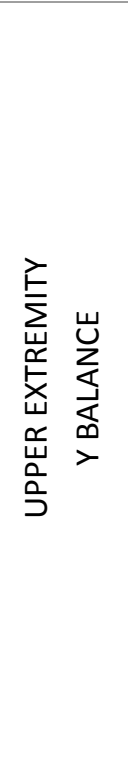 } & & Test & \multirow{2}{*}{ Left } & $67.75 \pm 20.47$ & 50 & $0000 *$ \\
\hline & & Re-test & & $71.41 \pm 18.46$ & 3.4 & 0.000 \\
\hline & IV & Test & & $65.45 \pm 20.50$ & & \\
\hline & & Re-test & Right & $69.62 \pm 18.16$ & 6.37 & $0.000^{*}$ \\
\hline & & Test & & $50.12 \pm 15.09$ & & \\
\hline & CIUPEDIOD & Re-test & Left & $53.02 \pm 14.85$ & 5.78 & $0.000^{*}$ \\
\hline & SUPERIUR & Test & Bight & $49.97 \pm 17.61$ & 758 & ค คคค* * \\
\hline & & Re-test & Kignt & $53.76 \pm 16.32$ & 1.58 & 0.000 \\
\hline & & Test & 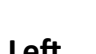 & $62.23 \pm 18.02$ & 367 & 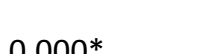 \\
\hline & & Re-test & Leit & $64.52 \pm 18.49$ & 3.67 & 0.000 \\
\hline & INFERIUR & Test & Right & $62.63 \pm 20.39$ & & \\
\hline & & Re-test & & $65.99 \pm 19.36$ & 5.31 & $0.000^{2}$ \\
\hline & & Test & left & $60.04 \pm 16.29$ & 491 & $0 \cap 0 \cap *$ \\
\hline & COMPOSITE reach distance & Re-test & Left & $62.98 \pm 15.55$ & 4.91 & $0.000^{*}$ \\
\hline & (\%) & Test & & $59.35 \pm 17.80$ & & \\
\hline & & Re-test & Right & $63.12 \pm 16.28$ & 6.36 & $0.000^{*}$ \\
\hline
\end{tabular}

${ }^{*} \mathrm{p}<0.005$

There was a statistically significant improvement in pre-test, post-test weight, BMI, body fat $\%$ and FMS values obtained from the study group $(\mathrm{p}<0.05)$. When the percentages of development were examined, it was observed that all the parameters related to body composition of the study group were changed in the expected way.

According to the pre-test and post-test lower extremity dynamic balance measurement results Anterior (A), Postero Medial (Pm), Postero Lateral (PL) and Composite values were found to be statistically significant $(\mathrm{p}<0.05)$. When the development percentages are examined, there is a positive change in all parameters. In the pre-test and post-test upper extremity dynamic balance measurement results; Balance scores of Medial (M), Superior (S),
Inferior (I) and Composite values were found to be statistically significant $(p<0.05)$. When the percentages of development were examined, Medial (M), Superior (S), Inferior (I) and there is a positive change in the composite values.

\section{Discussion}

This study aims to analyze the effects of eight week zumba exercise program on body composition, dynamic balance and functional movement capacity values of 15-17 year old female high school students with high body mass index (BMI>24.9) without sports background. The research supports "the hypothesis that regular participation in 8-week zumba exercise practices can improve body composition (body weight, body fat 
percentage, BMI parameters) parameters, functional movement capacity values and dynamic balance control of upper and lower extremities of young female high school students with high BMI values".

According to the findings of the study, during the 8 -week zumba training program, it is seen that it provided statistically significant improvement in total body weight loss $(p=.000)$, BMI parameter $(p=.000)$, body fat $\%$ $(p=.002)$, FMS values $(p=.000)$ and lower an upper extremity dynamic balance parameters $(\mathrm{p}=.000)$ (Tables 2-3). At this point, it is possible to talk about the positive effect of the zumba exercise program. In parallel with the study, Nedkova and Nikolova [7], in a series of studies covering university student, showed that zumba exercises with different methodologies increased the willingness of students to participate in these studies within the scope of physical education course. Ljubojević et al. [9] also stated that universal music rhythms also motivate participants to participate in regular physical activity through the desire to return to the zumba program over and over again. Group fitness exercises such as zumba are a sport that helps lose weight, positively affects BMI values and provides positive effects on body composition [6], as well as positive changes in women's body composition, it shows positive effects on motoric and functional abilities [9].

Studies based on overweight women show that the condition gained as a result of zumba exercises positively affects health and can be recommended as an effective method for weight control for overweight women [2830]. Baştuğ et al. [31]: reported that they observed positive effects on body composition and BMI values with 12-week zumba exercises applied to intervention group and these results show that the study is supported by the literature.

The realization of most of the daily activites depends on the provision of proper posture and balance in this position. It is known that balance is a risk factor especially for the occurrence of injuries in women [18] and studies have shown that there is a positive correlation between high BMI and postural instability, and this requires greater effort to maintain postural balance in the individual [17]. As a result of the study, it was observed that 8-week zumba exercise program made a significant difference in the improvement of post-exercise balance performance in dynamic balance tests similar to the literature, however, zumba studies also improved posture control. Many studies have reported that participation in regular zumba exercises creates significant positive changes in static and dynamic balance parameters $[13,32]$ and that zumba dance activities create significant improvements in static and dynamic balance values even in patients with Parkinson's disease [33]. In 2018, Baştuğ examined the effects of dance exercises on body composition, flexibility, balance and concentration, including zumba, and recommended regular dance exercises for the development of all these features [34].

Functional Movement Screen (FMS) test is used as a screening tool to evaluate functional mobility and postural stability [21]. FMS test aims to simulate the needs and constraints of physical activities in daily life. In order to perform physical activity applications correctly. FMS test should be considered as a guide in estimating dynamic balance scores in women and men [22, 23]. Determination of functional mobility capacity through FMS is an application method that tries to increase the educational activites of physical activities in daily life, including sports activities, to identify and simulate situational needs and constraints. Assuming that endurance, motion, flexibility and stability are a prerequisite for optimal athletic performace, FMS can be considered a safe screening tool to assess functional mobility and postural stability [21]. According to the results of the study, significant improvements were observed in FMS scores, which are the determinants of functional fitness, consisting of seven subtests, which measure functional fitness, and the results were statistically significant (Table 1). When health benefits are taken into consideration, it can be said that controlled zumba exercise studies will have a positive effect on FMS scores as a result of functional movement development.

\section{Conclusion}

The results of the study clearly show that the eightweek zumba training program (3 days-60 minutes per week) has produced significant positive improvements in body composition values, functional mobility assessment results and dynamic balance parameters of high school students with a high body mass index of 15-17 years of age. In line with this, zumba exercises can be suggested as an effective group exercise for this age group. Considering the benefits of regular physical activity, the importance of participation in fitness activites such as zumba in terms of health must be emphasized. And it is thought that such multi-repetitive training programs will provide benefits for individuals as increasing functional movement capacity values and dynamic balance parameters as well as improvement of BMI. In addition, zumba exercises can be suggested as an effective exercises for encouraging individuals with sedentary lifestyle to physical activity in long term weight control and body composition development.

\section{Conflict of interests}

The authors declare that there is no conflict of interests. 


\section{References}

1. Menteş E, Menteş B, Karacabey K. The investigation of physical activity levels and eating habits in adolescents. Eur J Exp Biol. 2014;4(1):693-8.

2. Obesity Rates According to WHO [Internet]. [Internet]. 2019. [updated 2019; cited 2019 Nov 93]. Available from: https:// www.who.int/news-room/fact-sheets/detail/obesity-andoverweight

3. Mehrabani J, Khazraei ZG. Overweight and Obesity: A Brief Challenge on Prevalence, Complications and Physical Activity among MenandWomen. MOJWomens Heal.2018;7(1):161-6. https://doi.org/10.15406/mojwh.2018.07.00161

4. Rossmeissl A, Lenk S, Hanssen H, Donath L, SchmidtTrucksäss A, Schäfer J. ZumBeat: Evaluation of a Zumba Dance Intervention in Postmenopausal Overweight Women. Sports. 2016;4(1): 5. https://doi.org/10.3390/sports4010005

5. Aukštuolytė E, Mauricienė V, Daunoravičienė A, Knispelytė $\mathrm{G}$, Berškiené K. Dynamics Of Body Composition And Body Image Of Sedentary Working Women Who Attend Zumba Or Functional Training Programs: Pilot Study. Baltıc J Sport Heal Sciences. 2018;2(109):2- 8. https://doi.org/10.33607/bjshs.v2i109.190

6. Haghjoo M, Islamic Azad University of Tehran, zar A, Jahrom University, Hoseini SA, ersity, Marvdasht,slamic Azad Univ. The Effect of 8 weeks Zumba Training on Women's Body Composition with Overweight. Jjums, 2016;14:21-30. https://doi.org/10.29252/jmj.14.2.21

7. Nedkova M, Nikolova E. Methodology for basic education of zumba fitness for university students. Act Phys Educ Sport. 2013;3(2):248-50.

8. İmamoğlu $\mathrm{M}$, Özdenk $\mathrm{S}$. The Effect of 12-Week Regular Pilates, Step and Zumba Training Program on Muscle and Fat Weight. JETS, 2019;7:33. https://doi.org/10.11114/jets.v7i11.4421

9. Ljubojević A, Jakovljević V, Popržen M. Effects of zumba fitness program on body composition of women. SportLogia. 2014;10(1):29- 33. https://doi.org/10.5550/sgia.141001.en.004L

10.Sanders ME. Zumba Fitness is Gold for All Ages. ACSM's Heal Fit J. 2012;16(2):25-28. https://doi.org/10.1249/01.FIT.0000413041.85247.01

11.Devi G. Effect Of Zumba Dance On Blood Pressure. 2016;8(6):2016. Devi G. Effect Of Zumba Dance On Blood Pressure. J Pharm Sci Res. 2016;8(6):501-5.

12.Jain PK, Nigudkar MR. Effect of 12 week zumba program and healthy diet on anthropometry, body composition and fitness parameters in working women. $J$ Nutr Heal Food Eng. 2016;5(4):672-7. https://doi.org/10.15406/jnhfe.2016.05.00180

13.Inouye J, Nichols A, Maskarinec G, Tseng C-W. A Survey of Musculoskeletal Injuries Associated with Zumba. Hawai'i J Med Public Heal. 2013;72(12):433-436.

14.DomenePA,MoirHJ,PummellE,KnoxA,EastonC.Thehealthenhancing efficacy of Zumba ${ }^{\circledR}$ fitness: An 8-week randomised controlled study. J Sports Sci. 2016;34(15):1396-404. https://doi.org/10.1080/02640414.2015.1112022

15.Sarvari S. The Effect of 3-Month Core Stabilization Training Program on Some Parameters in Elderly People [Ph. D. Thesis]. Gazi University; 2014.

16.Çuğ M. Effects of Swiss Ball Training On Knee Joint Reposition Sense, Core Strength And Dynamic Balance In Sedentary Collegiate Students. [Ph. D. Thesis]. Middle East Technical University; 2012.

17.Greve J, Alonso A, Bordini ACPG, Camanho GL. Correlation between body mass index and postural balance. Clinics. 2007;62(6):12-16. https://doi.org/10.1590/S1807-59322007000600010

18.Cass M, Kunnapas M, Lewis A, Maskell C, Milazzo, Alyssa Tamburello A. Comparing the effects of aquatic and land based exercise programs on balance in female. In: 20th Annual James Whalen Academic Symposium. Ithaka College; 2017. P.100-106

19.Okada T, Huxel KC, Nesser TW. Relationship Between Core Stability, Functional Movement, and Performance. J Strength Cond Res. 2011;25(1):252-61. https://doi.org/10.1519/JSC.0b013e3181b22b3e

20.Perry FT, Koehle MS. Normative Data for the Functional Movement Screen in Middle-Aged Adults. J Strength Cond Res. 2013;27(2):458-462. https://doi.org/10.1519/JSC.0b013e3182576fa6

21.Kraus K, Schütz E, Taylor WR, Doyscher R. Efficacy of the Functional Movement Screen: A Review. $J \quad$ Strength Cond Res. 2014;28(12):3571-3584. https://doi.org/10.1519/JSC.0000000000000556

22.Minick K, Kiesel KB, Burton L, Taylor A, Plisky P, Butler R. Interrater Reliability of the Functional Movement Screen. J Strength Cond Res. 2010;24(2):479-86. https://doi.org/10.1519/JSC.0b013e3181c09c04

23.Scudamore EM, Stevens SL, Fuller DK, Coons J. Use of Functional Movement Screen Scores to Predict Dynamic Balance in Physically Active Men and Women. J Strength Cond Res. 2019;33(7):1848-54. https://doi.org/10.1519/JSC.0000000000002829

24.Plisky PJ, Gorman PP, Butler RJ, Kiesel K. The Reliability of an Instrumented Device for Measuring Components of the Star Excursion Balance Test. North Am J Sport Phys Ther. 2009;4(2):92-6.

25.Gonell AC, Romero JAP, Soler LM. Relationship Between The Y Balance Test Scores And Soft Tissue Injury Incidence In A Soccer Team. Int J Sports Phys Ther. 2015;10(7):955966.

26.Demir A, Akın M, Küçükkubaş N. Comparison of dynamic balance properties of hypermobility in boys. Int $J$ Sport Exerc Sci. 2019;5(1):15-22. https://doi.org/10.18826/useeabd.510426

27.Cook G. Baseline sports-fitness testing. In: High Performance Sports Conditioning. eBook. Champaign, IL: Human Kinetics; 2001. P. 23-39.

28.Paoli A, Bianco A. What Is Fitness Training? Definitions and Implications: A Systematic Review Article. Iran J Public Heal. 2015;44(5):602-14.

29.Cugusi L, Wilson B, Serpe R, Medda A, Deidda M, Gabba S, vd. Cardiovascular effects, body composition, quality of life and pain after a Zumba ${ }^{\circledR}$ fitness program in Italian overweight women. J Sports Med Phys Fitness. 2016;56(3):328-35.

30.MicallefC. The effectiveness of an 8-week Zumba programme for weight reduction in a group of Maltese overweight and obese women. Sport Sci Health. 2014;10(3):211-217. https://doi.org/10.1007/s11332-014-0195-8

31.Baştuğ G, Özcan R, Gültekin D, Günay Ö. The effects of Cross-fit, Pilates and Zumba exercise on body composition and body image of women. International $J$ Sport Exerc Training Science. 2016;2(1):22-9. https://doi.org/10.18826/ijsets.25037

32.Donath L, Roth R, Hohn Y, Zahner L, Faude O. The effects of zumba training on cardiovascular and neuromuscular function in female college students. EurJSportSci.2014;14(6):569-77. https://doi.org/10.1080/17461391.2013.866168

33.Delextrat A, Bateman J, Esser P, Targen N, Dawes

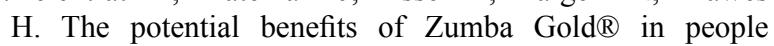
with mild-to-moderate Parkinson's: Feasibility and 
effects of dance styles and number of sessions. Complementary Therapies in Medicine, 2016;27:68-73. https://doi.org/10.1016/j.ctim.2016.05.009
34.Baştuğ G. Examination of Body Composition, Flexibility, Balance, and Concentration Related to Dance Exercise. Asian J Educ Train. 2018;4(3):210-5. https://doi.org/10.20448/journal.522.2018.43.210.215

\section{Information about the authors:}

Eroğlu Kolayiş İ.; (Corresponding Author); http://orcid.org/0000-0002-6031-9043; ikolayis@subu.edu.tr; Sakarya Applied Science University; Sakarya, Turkey.

Arol P.; http://orcid.org/0000-0001-6705-1687; pervinsonmez@hotmail.com; Adapazarı Vocational and Technical Anatolian High School; Sakarya, Turkey.

Cite this article as:

Eroğlu Kolayiş I, Arol P. The effect of Zumba exercises on body composition, , dynamic balance and functional fitness parameters in 15-17 years old women with high body mass index. Pedagogy of physical culture and sports, 2020;24(3):118-124.

https://doi.org/10.15561/26649837.2020.0303

This is an Open Access article distributed under the terms of the Creative Commons Attribution License, which permits unrestricted use, distribution, and reproduction in any medium, provided the original work is properly cited (http://creativecommons.org/licenses/by/4.0/deed.en).

Received: 12.11.2019

Accepted: 16.12.2019; Published: 05.01.2020 